\title{
Atividades práticas e ensino de Ciências nos anos finais do Ensino Fundamental
}

\section{Practical Activities and Science teaching in the Elementary School final years}

\section{Actividades prácticas y la enseñanza de las Ciencias en los años finales de la Enseñanza Fundamental}

\author{
Sandra Aparecida de Oliveira Souza ${ }^{1}$ \\ Maria de Fátima Ramos Andrade ${ }^{1}$
}

DOI: http://dx.doi.org/10.20435/serie-estudos.v24i51.1169

\begin{abstract}
Resumo: As atividades práticas podem contribuir de forma atraente e significativa para a eficácia no processo de ensino e aprendizagem em Ciências. Em vista disso, o presente estudo se propôs a analisar como os professores de Ciências concebem a utilização de atividades práticas nas suas aulas e quais as estratégias que empregam. A fim de realizarmos essa investigação, optamos por uma pesquisa qualitativa (particularmente um estudo de caso) em que acompanhamos, por meio da observação das aulas e de entrevistas semiestruturadas, o trabalho de quatro professores de Ciências de uma escola estadual de tempo integral, localizada na cidade de São Paulo. Apoiamo-nos, para isso, na revisão literária que congrega o ensino de Ciências numa perspectiva histórica e social; a formação e a prática docente na área de Ciências; e o conceito de atividades práticas. Os resultados obtidos mostraram que, na visão dos professores, as atividades práticas são importantes para estimular a observação e a curiosidade, permitindo maior compreensão dos conteúdos e melhoria na aprendizagem científica.
\end{abstract}

Palavras-chave: Atividades práticas; ensino de Ciências; prática docente.

Abstract: Practical activities can contribute in an engaging and meaningful way to the effectiveness in the process of teaching and learning Science. Therefore, the present study aimed to analyze how science teachers conceive the use of practical activities in their classes and which strategies. In order to accomplish this research, we decide for a qualitative research (particularly a case study) in which we followed, through the observation of the classes and semi-structured interviews, the work of four Science teachers from a full-time public school, located in the city of Sao Paulo. For such purpose, we focused our study on the literary review which congregates the teaching of Science in a historical and social perspective; training and teaching practice in the area of Science; and the concept of practical activities. The acquired results demonstrated that, according to those teachers, the practical activities are important to stimulate observation and curiosity, allowing contents greater understanding and scientific learning improvement.

${ }^{1}$ Universidade Presbiteriana Mackenzie, São Paulo, São Paulo, Brasil. 
Keywords: Practical activities; Science teaching; teaching practice.

Resumen: Las actividades prácticas pueden contribuir de forma atractiva y significativa a la eficacia en el proceso de enseñanza y aprendizaje en Ciencias. En vista de ello, el presente estudio se propuso analizar cómo los profesores de Ciencias concibe la utilización de actividades prácticas en sus clases y cuáles son las estrategias que emplean. A fin de realizar esta investigación, optamos por una investigación cualitativa (particularmente un estudio de caso) en que acompañamos, por medio de la observación de las clases y de entrevistas semiestructuradas, el trabajo de cuatro profesores de Ciencias de una escuela estadual de tiempo completo, localizada en la ciudad de São Paulo. Nos apoya, para ello, en la revisión literaria que congrega la enseñanza de las ciencias desde una perspectiva histórica y social; la formación y la práctica docente en el área de Ciencias; y el concepto de actividades prácticas. Los resultados obtenidos mostraron que, en la visión de los profesores, las actividades prácticas son importantes para estimular la observación y la curiosidad, permitiendo la mayor comprensión de los contenidos y la mejora en el aprendizaje científico.

Palabras clave: Actividades prácticas; enseñanza de Ciencias; práctica docente.

\section{INTRODUÇÃO}

Ensinar Ciências é um grande desafio, realidade evidenciada na prática docente junto a uma população de estudantes adolescentes, muitas vezes desmotivados. A falta de interesse, somada às dificuldades que os alunos têm em assimilar conteúdos científicos, pressupõe uma difícil tarefa para o professor, que ainda tem que lidar com sua "má formação". Essas constatações apontam para uma reflexão a respeito da construção do conhecimento científico em sala de aula, de modo a superar a cultura da transmissão de informação descontextualizada, "formada por uma coleção de fatos, descrição de fenômenos, enunciados de teorias a decorar" (KRASILCHIK, 2012, p. 64), tão comuns ainda hoje.

Desse modo, um dos muitos desafios colocados frente ao ensino de ciências é permitir que os alunos compreendam como a ciência é construída e quais suas aplicações mais importantes. Além disso, é importante que eles analisem as implicações sociais do desenvolvimento científico e as relações entre atividades científicas e tecnológicas e a melhoria na qualidade de vida. Assim,

[...] parece que a aquisição do conhecimento científico, longe de ser um produto espontâneo e natural, de nossa interação com o mundo dos objetos, é uma laboriosa construção social ou, melhor ainda, uma "reconstrução", que poderá ser alcançada por meio de um ensino eficaz que saiba enfrentar as dificuldades desse aprendizado. (POZZO; CRESPO, 2009, p. 244)

Na perspectiva de contribuir para a eficácia na aprendizagem científica, pesquisadores como Krasilchik (2012); Andrade e Massabni (2011); Pozzo e 
Crespo (2009); Bizzo (2002), sinalizam para a importância do desenvolvimento de atividades práticas nas aulas de Ciências. Constata-se, porém, que o significado dessa abordagem metodológica não apresenta consenso entre os autores citados e muitos outros analisados. Assim, para a presente pesquisa, utilizamos a concepção de atividade prática proposta por Hodson (1988) e aprimorada por Dourado (2001) e Leite (2000), porquanto um recurso didático que inclui todas as atividades em que o aluno esteja ativamente envolvido (no domínio psicomotor, afetivo e cognitivo). De acordo com essa definição, a atividade prática inclui, entre outros, o trabalho laboratorial e o trabalho de campo.

Considerando o exposto, inicialmente apresentamos, numa perspectiva histórica e social, os desafios no ensino de Ciências e exploramos o conceito de atividades práticas. Na sequência, os dados gerados na pesquisa de campo são apresentados e analisados, e por último tecemos algumas conclusões.

\section{OS DESAFIOS NO ENSINO DE CIÊNCIAS}

No Brasil, durante a década de 1980, aspectos como a redemocratização do país, a defesa do meio ambiente e a luta pela paz mundial passaram a exigir a formação de estudantes que pudessem viver numa sociedade mais igualitária. As propostas para o ensino de Ciências questionavam o racionalismo da atividade científica, e acabaram por reconhecer que a ciência não se constituía numa atividade essencialmente objetiva e socialmente neutra.

Segundo Krasilchik,

Na medida em que a Ciência e a Tecnologia foram reconhecidas como essenciais no desenvolvimento econômico, cultural e social, o ensino de Ciências em todos os níveis foi também crescendo de importância, sendo objeto de inúmeros movimentos de transformação do ensino, podendo servir de ilustração para tentativas e efeitos das reformas educacionais. (KRASILCHIK, 2000, p. 85).

A democratização do acesso à educação fundamental pública, que se iniciou a partir da década de 1970, se fortaleceu na década de 1990 com o slogan "escola para todos", o que pressupunha uma "ciência para todos". Assim, pesquisadores e educadores preocupavam-se com a qualidade desse ensino. Segundo Delizoicov, Angotti e Pernambuco: 
O desafio de pôr o saber científico ao alcance de um público escolar em escala sem precedentes - público representado pela primeira vez em nossas histórias, por todos os segmentos sociais e com a maioria expressiva oriunda das classes e culturas que até então não frequentaram a escola, salvo exceções - não pode ser enfrentado com práticas docentes das décadas anteriores ou da escola de poucos e para poucos. (DELIZOICOV; ANGOTTI; PERNAMBUCO, 2011, p. 33).

Com o intuito de superar estas e muitas outras dificuldades, regulamentar e promover a qualidade do ensino, dois importantes instrumentos legais são elaborados na década de 1990:

- A Lei de Diretrizes e Bases da Educação Nacional (LDBEN n. 9394/96), em cujo artigo 26, estabelece que a formação básica do cidadão na escola fundamental exige o "estudo da língua portuguesa e matemática, o conhecimento do mundo físico e natural e da realidade política, especialmente a do Brasil". No seu artigo 32, objetiva "a compreensão do ambiente natural e social, do sistema político, da tecnologia, das artes e dos valores em que se fundamenta a sociedade".

- Os Parâmetros Curriculares Nacionais (PCNs) para o ensino fundamental (BRASIL, 1998), sugere um percurso profícuo para a realização de trabalhos interdisciplinares, pois apresenta linhas norteadoras para a orientação curricular em áreas interligadas através de temas transversais (Ética, Saúde, Meio Ambiente, Orientação Sexual, Pluralidade Cultural, Trabalho e Consumo). Dentro de cada área de conhecimento são organizados eixos temáticos, sendo que, na área de Ciências Naturais, os eixos propostos foram: Ambiente, Ser Humano, Recursos Tecnológicos, Terra e Universo.

Nesse contexto, as propostas curriculares enfatizavam a necessidade de levar os estudantes a desenvolverem o pensamento reflexivo e crítico, a questionarem as relações entre ciência, tecnologia, sociedade e ambiente e a se apropriarem de conhecimentos relevantes científica, social e culturalmente. Para tanto, "os cursos deveriam incluir temas relevantes que tornassem os alunos conscientes de suas responsabilidades como cidadãos, pudessem participar de forma inteligente e informada de decisões que iriam afetar a comunidade" (KRASILCHIK, 2012, p. 89).

Um aspecto bastante importante nesse cenário foi a inclusão de um novo componente no vocabulário do ensino de ciências, a alfabetização científica, ca- 
racterizada por objetivos requeridos pela sociedade, qual seja a formação cidadã dos estudantes para o domínio e uso dos conhecimentos científicos de modo a serem úteis nas suas vidas.

Constata-se, pelo exposto, que inúmeros são os desafios para promover condições e oportunidades para o desenvolvimento de uma educação de qualidade, particularmente a científica, num cenário representado por um público estudantil heterogêneo, oriundo de todos os segmentos sociais e que, mesmo em face do crescimento da influência construtivista nas diretrizes de ensino nesse período, poucas e rasas são as discussões sobre o papel do docente na criação em sala de aula de um clima de liberdade intelectual. Assim, os livros didáticos continuaram a servir de apoio aos professores, em aulas essencialmente expositivas e descontextualizadas.

Inicia-se o século XXI e ainda é evidente o descompasso entre os propósitos educacionais do ensino de Ciências e as possibilidades da sua concretização em sala de aula. "A veiculação do conhecimento científico e tecnológico não acabado, não neutro, social e historicamente construído, consenso em todas as propostas curriculares" (DELIZOICOV; ANGOTTI; PERNAMBUCO, 2011, p. 67), esbarra na dificuldade dos professores em romper com uma postura positivista da ciência e, também, com o caráter conservador e autoritário nas suas práticas educativas. Corrobora para esse quadro a ineficiente formação geral, científica e pedagógica e as precárias condições de trabalho do professor.

Entende-se que não basta estruturar cuidadosa e fundamentalmente um currículo, é necessário que o professor seja preparado para desenvolvê-lo, pois a compreensão da ciência e como ela é construída, aumentam a confiança docente e melhora suas habilidades para ensinar Ciências (CARVALHO; GIL-PÉREZ, 2011).

Esse quadro, aliado a outros fatores presentes no cotidiano escolar como, por exemplo, um ensino de memorização de fatos e conceitos, falta de vínculo com a realidade dos alunos, ausência de coordenação com outras disciplinas, aulas mal ministradas, número de atividades práticas insuficientes, reflete a precariedade na formação dos professores e atinge de maneira acachapante o desempenho e formação dos alunos. A realidade aqui descrita é evidenciada em outras pesquisas como as de Krasilchik, (2012), Bizzo (2005), Carvalho e Gil-Pérez (2011), e é demonstrada nos resultados de avaliações externas, tais como PISA (Programa Internacional para a Avaliação de Alunos), Prova Brasil e SAEB (Exame Nacional de Avaliação Básica). 
Por fim, compreender os desafios dos anos finais do ensino fundamental (6ำ ao 9ㅇ ano, de acordo com a Resolução CNE/CEB n. 3/2005), além de exigir uma reflexão sobre a formação e a prática docente, requer o entendimento sobre as mudanças pelas quais os estudantes passam, como eles se relacionam com o mundo e, também, de que forma esses adolescentes constroem seu conhecimento, particularmente o científico. Afinal, grande parte do sucesso ou fracasso da aprendizagem em sala de aula está intrinsecamente ligada ao desempenho destes dois sujeitos, o professor e o aluno.

\section{ATIVIDADES PRÁTICAS E A AÇÃO DOCENTE}

A definição de atividades práticas para o ensino de Ciências é muito controversa, pois está intimamente ligada às concepções epistemológicas que cada pesquisador adota e as traduz na prática, retratando suas convicções e crenças, quer da construção e desenvolvimento científico, quer de ensino aprendizagem em Ciências (DOURADO, 2001).

Assim, no presente trabalho, utilizamos a concepção de atividade prática proposta por Hodson (1998) e complementada por Leite (2000) e Dourado (2001), como sendo um recurso didático que inclui todas as atividades em que o aluno esteja ativamente envolvido (no domínio psicomotor, afetivo e cognitivo). $\mathrm{Na}$ figura 1, pode ser observada uma estrutura para tal concepção.

Figura 1 - Relação entre experimento, trabalho laboratorial, trabalho de campo e atividades práticas.

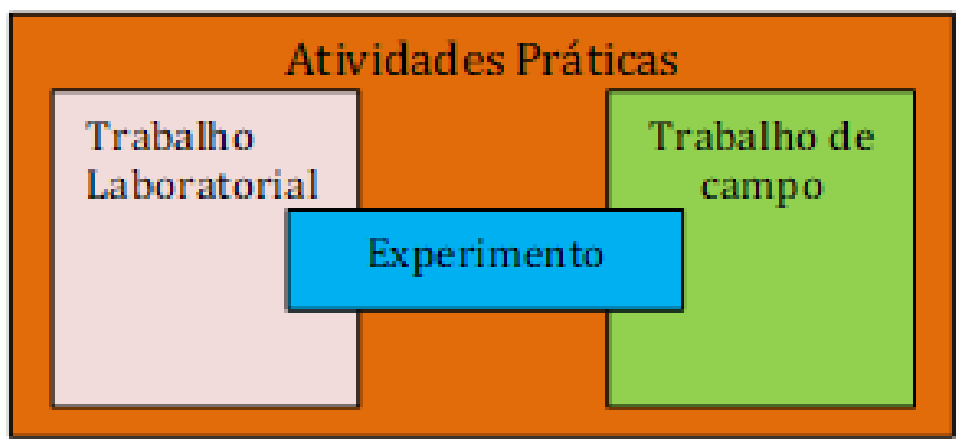

Fonte: Hodson (1988) e Leite (2000). 
A atividade prática, nesse contexto, engloba o trabalho de campo (realizado ao ar livre e onde, geralmente, os acontecimentos ocorrem naturalmente) e o trabalho laboratorial (requer o uso de materiais de laboratório e que podem ser realizados em laboratórios ou sala de aula normal). No entanto há atividades práticas que não se enquadram em nenhum desses dois tipos, delas são exemplos as atividades de pesquisa de informação na biblioteca ou internet, simulações informáticas, resolução de problemas. Outras atividades práticas envolvem controle e manipulação de variáveis e são chamadas por isso de trabalho experimental. Algumas atividades laboratoriais e de campo apresentam essas características e, assim, são chamadas atividades laboratoriais de tipo experimental (LEITE, 2000).

À medida que foram mudando os objetivos do ensino de Ciências, as justificativas para a necessidade de aulas práticas também eram alteradas, passando da comprovação do que era aprendido nas aulas teóricas até a função de vivenciar o processo de investigação científica.

Ao tratar sobre esse assunto, Hodson (1988) pondera que muito do que ocorre nas aulas de ciências sob o nome de atividade prática, é confuso e sem valor educacional real, pois os professores não reconhecem as diferenças básicas entre o papel dos experimentos em ciência e no ensino de ciências, estabelecendo-se assim uma distinção entre trabalho prático (métodos ativos de aprendizagem) e trabalho de laboratório, e entre trabalho de laboratório e experimentos. Daí a importância, segundo o autor, do professor ter bem claro em cada aula os objetivos relacionados a aprender ciência, aprender sobre a ciência e fazer ciência.

Além dessas distorções, nota-se, no contexto escolar, a existência de algumas crenças a respeito do desenvolvimento das atividades práticas, que perpetuam o olhar equivocado sobre a ciência e servem de argumento para não se inserir essas atividades no ensino.

\section{PROCEDIMENTOS METODOLÓGICOS}

A escolha por uma pesquisa qualitativa, em particular o estudo de caso, levou em conta o interesse de ter acesso aos documentos e ao contexto natural em que ocorrem as atividades escolares, as interações entre os seus partícipes e as experiências surgidas nesse ambiente. Assim, esta pesquisa foi desenvolvida numa escola estadual que faz parte do Programa Ensino Integral (PEI) situada na Zona Leste da cidade de São Paulo. É uma unidade diferenciada, com sala de leitura, 
laboratório de Ciências e Matemática, sala multiuso, laboratório de informática, além de equipamentos multimídia nas salas de aula. Em 2016, tinha cerca de 280 alunos distribuídos em 11 salas: 4 de $60^{\circ}$ anos, 3 de 7ㅇs anos, 2 de $8 \div$ s anos e 2 de 9 os anos. Na área de Ciências trabalhavam quatro professores concursados, com larga experiência docente e que atuavam em regime de dedicação exclusiva (40 horas semanais). Seguimos os seguintes passos: aplicação de questionários, entrevistas semiestruturadas e observação.

$\mathrm{Na}$ análise das respostas dadas durante as entrevistas, buscamos identificar como os professores definiam atividades práticas e sua importância para o ensino de Ciências. Também nos interessou entender como essas atividades eram planejadas e quais desafios eles encontravam para desenvolvê-las. Para complementar, questionamos sobre as experiências de cada um com a realização de atividades práticas na formação inicial e pedimos que eles sugerissem formas de aprimorar o desenvolvimento dessas atividades nas aulas de Ciências. Nas aulas, investigamos as estratégias desenvolvidas, a organização para a atividade prática (espaço utilizado, recursos, disposição espacial dos alunos, fatores ambientais), a gestão do professor, a interação dos sujeitos, o ambiente pedagógico e a pertinência dos conteúdos abordados com relação à atividade proposta e, por fim, os desafios encontrados.

Tanto para as observações das aulas quanto para as respostas das entrevistas, estabelecemos quatro categorias para direcionar as análises. São elas:

1) Visão do professor sobre as atividades práticas no Ensino de Ciências;

2) Planejamento das atividades práticas (importância e procedimentos);

3) Desenvolvimento das atividades práticas em aula (estratégias, espaços, recursos, interação professor / aluno, avaliação e desafios);

4) Relevância da formação inicial e continuada (preparação do professor para sua prática).

Para André (2013, p. 101), a "categorização por si só não esgota a análise". Assim, é necessário que o pesquisador acrescente algo ao que já se conhece sobre o assunto, superando assim a simples descrição dos fatos. Nesse contexto, abordamos a análise dos dados coletados em diálogo com o referencial teórico e, ao fazer isso, estabelecemos conexões e relações que nos possibilitaram indicar o que descobrimos de forma mais abrangente e que esperamos contribua para 
a reflexão sobre o desenvolvimento de atividades práticas no Ensino de Ciências, com vistas à melhoria nas condições da prática do professor e na sua formação.

\section{VISÃO DO PROFESSOR SOBRE AS ATIVIDADES PRÁTICAS NO ENSINO DE CIÊNCIAS}

Agrupamos as respostas de acordo com as categorias analíticas estabelecidas: Visão do professor sobre as atividades práticas no Ensino de Ciências; Planejamento das atividades práticas (importância e procedimentos); Desenvolvimento das atividades práticas em aula (estratégias, espaços, recursos, interação professor / aluno, avaliação e desafios); Relevância da formação inicial e continuada (preparação do professor sua prática). Os professores foram representados por A, B, C e D como forma de preservar suas identidades.

A primeira pergunta da entrevista feita aos professores foi o que eles entendiam por atividades práticas no ensino de Ciências. Para a maioria, atividades práticas significam contextualizar o conhecimento, estar no laboratório e que proporcionam aprendizado. As falas a seguir ilustram esses aspectos:

São atividades que contextualizam o conteúdo, melhoram o entendimento da teoria. Surgem algumas palavras como lúdico, desafio, motivação. (Professor A).

Quando penso em atividades práticas, logo penso no laboratório, nos materiais de um laboratório. Nessa escola temos laboratório e fica mais fácil. Só uma observação, nem todos os experimentos necessitam de sala específica. (Professor B).

Tudo aquilo que consiga construir, sistematizar. Nem todo o experimento dá certo, é legal que dê errado para poder discutir (questionamentos). (Professor C).

São atividades que proporcionam uma ampliação no conhecimento que o aluno possui e, assim, possibilitam uma melhor compreensão daquilo que o professor ensina em aula. O ensino no laboratório tem que ter organização e gerar interesse nos alunos. (Professor D).

Para caracterizar as atividades práticas, os professores $B, C$ e D associam às aulas no laboratório com o intuito de fazer experimentos. Esse olhar não encontra respaldo na definição que fizemos neste trabalho: um recurso didático à disposição do professor, que inclui todos os trabalhos em que o aluno esteja ativa, emocional 
e cognitivamente envolvido e, nesse contexto, engloba o trabalho laboratorial, o trabalho de campo e o trabalho experimental.

O fato de os professores entenderem a aula prática como aquela em que ocorre uma prática laboratorial, corrobora os dados encontrados por Andrade e Massabni (2011). Na pesquisa por eles realizada, constatou-se que a maioria das professoras de Ciências entrevistadas tinha a mesma compreensão limitada dessas atividades.

Os professores $A, B$ e $D$ atribuem às atividades práticas fatores importantes para o ensino/aprendizagem: a contextualização do conteúdo, o desafio, a realização, a construção de algo e a ampliação do conhecimento. Unir o trabalho prático à relevância dos conteúdos como esses professores fizeram está de acordo com as argumentações de Krasilchik (2012), que destaca o poder desse encontro para o progresso real do ensino de Ciências.

Sobre a importância das atividades práticas, todos os professores atribuíram a essas atividades a motivação para as aulas, como podemos observar nos trechos a seguir:

Elas motivam para as aulas. (Professor A).

Eles (alunos) ficam instigados a entender diversos fenômenos. (Professor B).

Eles (alunos) trouxeram exemplos do dia-a-dia e foi muito legal. (Professor C).

As atividades práticas podem despertar a curiosidade [...]. (Professor D).

A motivação dos alunos é realmente um aspecto positivo para que eles "entrem no clima" da aula, mas só isso não determina o sucesso da atividade. Para Praia, Cachapuz e Gil-Pérez (2002), a tentação em experimentar e espetacularizar os fenômenos que podem ocorrer, pode gerar o efeito contrário, ou seja, os aspectos motivacionais perdem o sentido trazendo prejuízo para a aprendizagem.

Associado à importância das atividades práticas, um fator importante aparece na fala do Professor $D$, a necessidade de um trabalho conjunto para promoção da aprendizagem: "[...] para serem desenvolvidas plenamente é necessária a participação do professor, do aluno e da gestão. Assim, ocorre um aprendizado gostoso e investigativo".

Para contextualizar a resposta, os professores deram exemplos de atividades que eles fizeram com os estudantes, procurando mostrar a importância das atividades práticas: 
Por exemplo, o plantio de vegetais durante a eletiva neste semestre motivou uma das alunas a fazer horta em casa. Ela preparou o solo do quintal e plantou algumas coisas. Achei bem legal. (Professor A).

Na eletiva do primeiro semestre que você viu na apresentação dos trabaIhos do final de semestre, o conteúdo de química foi bem explorado, pois fabricamos sabão, detergente [...] os alunos se interessaram muito e, por isso, acho que compreenderam melhor alguns assuntos que eles consideram difíceis, como as transformações químicas. (Professor B).

No caso da cultura de fungos que eu já falei, muitos "não deram certo" (aspas a pedido da professora) e foi muito rica a discussão. (Professora C).

Acreditamos que os exemplos da prática pedagógica, bem como as visões que os professores têm sobre as atividades práticas e que foram relatadas nas suas respostas, estão intimamente ligados a crenças, saberes e valores que os docentes possuem, enfim, estão integradas à sua história de vida. Duas dessas crenças já foram discutidas anteriormente e podem ser evidenciadas na categoria que acabamos de apresentar e analisar: a garantia da motivação dos alunos frente ao desenvolvimento de atividades práticas e a necessidade de laboratório para realizá-las.

Ponte (1992) argumenta que as crenças representam uma parte do conhecimento relativamente pouco elaborada e com fraca confrontação com a realidade, e as concepções, por outro lado, correspondem "ao pano de fundo organizador dos conceitos" (PONTE, 1992, p. 196) tendo uma natureza fundamentalmente cognitiva. Ele também salienta que "estreitamente ligadas às concepções estão as atitudes, as expectativas e o entendimento que cada um tem do que constitui o seu papel numa dada situação" (p. 196), condicionando a forma de abordagens das tarefas que nem sempre são as mais adequadas.

Compreender as crenças ou a estrutura das crenças dos professores torna-se importante, na medida em que elas podem influenciar percepções e julgamentos das pessoas, que por sua vez podem afetar o comportamento dos professores em sala de aula (BEJARANO; CARVALHO, 2003). Assim, confiamos que dar oportunidade ao professor durante a sua formação e na sua prática de refletir sobre suas concepções e crenças favoreça a discussão crítica das situações de ensino e aprendizagem em Ciências. 


\section{PLANEJAMENTO DAS ATIVIDADES PRÁTICAS}

A importância do planejamento das aulas foi assim descrita:

Tem que ter um planejamento e o professor precisa ter em mente que nem tudo pode dar certo e aí tem que reavaliar. (Professor C).

Tenho cuidado de seguir o planejamento, pois ele é importante para ter uma direção. (Professor A).

Os professores utilizam o espaço da escola para realizar o planejamento de suas aulas, mas muitas vezes complementam o trabalho em suas residências. As falas a seguir ilustram essa constatação:

Planejo minhas atividades na escola, durante as aulas destinadas a isso. (Professor A).

[...] inclusive, nos finais de semana preparo aulas. (Professor B).

Preparo as atividades aqui na escola, mas muitas vezes preparo em casa, também. (Professor C).

Os materiais consultados para planejar as aulas são: livros didáticos, revistas, internet e os Cadernos da Secretaria da Educação do Estado de São Paulo:

Consulto livros didáticos, revistas e a internet. (Professor A).

Sigo o conteúdo (currículo do Estado) e utilizo os cadernos da Secretaria da Educação. Uso também o livro didático e a internet. (Professora C).

A escolha das atividades vem ao encontro do que está contido no caderno do aluno (Secretaria da Educação) [...] (Professor D).

A pertinência dos temas para planejar foi citada apenas pelo Professor D quando ele alega que dá "prioridade às atividades que exercem grande fascínio por parte dos alunos". Com relação a essa resposta, não conseguimos determinar como a escolha é realizada na prática.

Além das respostas que mostraram de forma implícita (utilização do material pedagógico fornecido pela Secretaria da Educação) a preocupação dos professores em acompanhar os preceitos estabelecidos no currículo do Estado de São Paulo, pudemos notar que, na escola pesquisada, há um esforço coletivo para planejar de forma significativa as atividades que serão trabalhadas com os alunos. Reuniões gerais e de área são realizadas frequentemente. Esse fato não passou despercebido pela Professora B: "Atribuo à forma como a escola é gerida 
a cobrança pela preparação dos professores". Ela ainda confidenciou que "nunca estudei tanto como nessa escola e acho isso muito importante, pois tira o professor da mesmice".

Ao presenciar uma dessas reuniões, na qual os professores participaram ativamente e empenhados na estruturação das disciplinas eletivas, constatou-se que as propostas da Coordenadora promoveram o envolvimento e a sensibilização dos professores. Assistindo a outras reuniões ao longo do segundo semestre de 2016, observamos também o desenvolvimento das propostas e o cumprimento das decisões no cotidiano da escola. Associei o que vi ao conceito de escola reflexiva desenvolvido por Isabel Alarcão. Segundo ela, uma escola reflexiva é uma "organização (escolar) que continuadamente se pensa a si própria, na sua missão social e na sua organização, e se confronta com o desenrolar da sua atividade em um processo heurístico simultaneamente avaliativo e formativo" (ALARCÃO, 2001, p. 25).

O planejamento contínuo foi citado pelos professores como essencial no sucesso das atividades realizadas e no bom desempenho dos alunos, e o acompanhamento da gestão escolar foi citado pelos professores como essenciais no sucesso das atividades realizadas. O professor B, sobre formação continuada, completou: "Aqui na escola temos as reuniões de formação em que dividimos experiências, um professor ajuda o outro. Isso ajuda bastante. " Tivemos a oportunidade de presenciar essas reuniões e constatamos o empenho em promover o envolvimento e a sensibilização dos professores.

Evidentemente, muitas são as dificuldades para planejar uma atividade prática, causando por vezes a não utilização dela nas aulas de Ciências. Sobre esse assunto, Villani (1991, p. 167) argumenta que considerar o planejamento como uma atividade que merece um esforço adicional é fundamental para que ele possa ter efeitos consideráveis.

\section{DESENVOLVIMENTO DAS ATIVIDADES PRÁTICAS EM AULA}

Quando questionados sobre as condições para o aperfeiçoamento na realização de atividades práticas nas aulas de Ciências, os professores reportaram-se à preparação adequada para ministrarem essas aulas, aos aspectos materiais e também à necessária integração entre os sujeitos da comunidade escolar: 
Os cursos de formação de professores precisam estimular e orientar para sua prática. As escolas devem oferecer os recursos mínimos necessários para que elas ocorram, tempo para planejamento, materiais e locais adequados. (Professor A).

Acho que a preparação dos professores é o mais importante. (Professor B). é necessária a participação ativa e o envolvimento de todas as pessoas da escola, alunos, professores, gestores, funcionários e o apoio da família destes alunos. (Professor D).

Em contrapartida, os professores relatam as "facilidades" que encontram na Unidade Escolar para desenvolver adequadamente as atividades práticas. Por fazer parte do $\mathrm{PEI}$, a escola tem muitos recursos, quando comparados às outras unidades estaduais que não fazem parte do mesmo programa. Esse é um aspecto positivo evidenciado pelos docentes e que auxilia no trabalho pedagógico:

Por ser uma escola de tempo integral e possuir laboratório, fica mais fácil desenvolver as atividades. (Professor D).

A escola possui recursos tecnológicos que agilizam o desenvolvimento das atividades. (Professor A).

A escola apresenta recursos como o laboratório de ciências, datashow em cada sala, notebook para cada aluno, sala multiuso, sala de leitura. (Professora B).

A única resposta dissonante foi da Professora C: "O que eu faço aqui já fazia em outras escolas e acredito que aqui é a mesma coisa". A reflexão que se faz dessa fala nos conduz ao trabalho da professora em sala de aula, ao envolvimento dela com as propostas da escola e com seus pares, portanto há de se indagar qual o motivo da indiferença com fatores que a maioria dos professores julgou importante para desenvolver as atividades práticas. Quando questionados sobre as dificuldades que encontram para realizar as atividades, os professores citam a falta de material de consumo:

O principal problema é a falta de materiais de consumo. Dependendo do experimento, o professor compra. (Professor B).

Minha dificuldade é não ter todos os materiais de consumo. (Professor C).

Os estudos realizados por Krasilchik (2012) fortalecem o aspecto negativo que a deficiência de materiais causa. Ela argumenta que "esta situação leva muitos 
professores a resignarem-se a não dar aulas práticas. Alguns renitentes acabam dando, tendo, porém, que gastar muito de seu tempo e dinheiro para obtenção do material de consumo, indispensável" (KRASILCHIK, 2012, p. 62).

O número excessivo de alunos durante as aulas no laboratório foi outro fator relatado durante as entrevistas como um entrave para a realização dos experimentos: "Minha dificuldade é com o número excessivo de alunos por sala nas aulas práticas" (Professor D).

Convém esclarecer que, nas aulas de Práticas Experimentais nessa escola, a média de alunos por turma é de 25 , número esse que corresponde satisfatoriamente à capacidade do laboratório. Mesmo com essa realidade, algumas razões podem ser listadas para que um número inadequado de alunos em sala consista num complicador durante a aula, e prejudique a aprendizagem: indisciplina; acidentes, principalmente no laboratório; inexistência de uma atenção mais individualizada.

Outro aspecto dificultador citado pela Professora B é a excessiva burocracia: "outro problema é a burocratização, temos que preencher várias fichas de cada aluno, de cada aula. Ao mesmo tempo em que isso nos ajuda no acompanhamento do processo, também exige muito tempo que poderia ser usado para outras coisas".

Caracteriza-se nessa resposta o dilema do professor, ao mesmo tempo que ele rejeita o trabalho burocrático, admite a importância deste. Em suma, para o desenvolvimento eficaz de aulas que usam atividades práticas, vários aspectos devem ser considerados, e a boa formação docente é um deles.

\section{RELEVÂNCIA DA FORMAÇÃO INICIAL E CONTINUADA (PREPARAÇÃO DO PROFESSOR E SUA PRÁTICA)}

Com o intuito de investigar a visão dos professores sobre a importância de se trabalhar com atividades práticas, pedimos um relato sobre as aulas práticas que eles tiveram na formação inicial e perguntamos se elas oportunizaram uma experiência positiva. Por fim, questionamos a influência delas nas aulas que eles ministram. Eles responderam assim:

Acho que a formação acadêmica inicial não é suficiente para a realização de atividades práticas. O que contribuiu para a consolidação da minha formação para esse objetivo foi trabalhar em indústria química e farmacêutica. (Professor A). 
Foi uma boa experiência (formação inicial) e me ajudou muito no cotidiano da escola. Considero a formação continuada muito importante também. (Professor B).

Tive aulas de Biologia dos invertebrados, Química, Bioquímica. Também sou formada em Farmácia. Estas experiências foram positivas e várias coisas que aprendi me ajudaram quando comecei a lecionar e ao longo da minha carreira [...] mas continuo a estudar. A formação continuada é muito importante para me manter atualizada. (Professor C).

Minha formação inicial me deu condições para que eu pudesse realizar com segurança algumas atividades, mas a formação continuada proporcionou mais segurança e ampliou meu leque de atividades. (Professor D).

O conjunto de professores da escola pesquisada parece encerrar profissionais bem formados e bem preparados para a ação docente, e que abraçaram as diretrizes do PEI. Também, preocupam-se em compartilhar as experiências e acompanhar os alunos na direção da aprendizagem científica. Eles consideram a formação inicial importante, mas salientam que continuar estudando é essencial para o exercício docente.

\section{AS AULAS}

A observação das aulas foi mais um instrumento utilizado em nosso estudo para investigar o desenvolvimento das atividades práticas. Para a análise, consideramos: a gestão da aula; o discurso do professor; a interação dos sujeitos (aluno e professor); o caráter da atividade prática (demonstração, verificação, experimentação); os espaços utilizados para a aula; os recursos disponíveis e, por fim, os desafios encontrados.

Para corroborar esse discurso, acompanhamos esses professores durante suas aulas e constatamos que um deles demonstrou claramente um descompasso entre a sua fala e o modo como ele executa essas atividades. Os outros professores, no entanto, deixaram transparecer na sua prática as convicções relatadas. Assim, ao menos nos momentos observados, esses docentes incentivaram os alunos e proporcionaram uma atmosfera para a construção do conhecimento.

Essas constatações nos levam a crer que a prática pedagógica, bem como as visões que os professores têm sobre as atividades práticas estão intimamente ligadas a crenças, saberes e valores que eles possuem e à forma como eles pensam 
que o aluno aprende. Portanto dar oportunidade ao professor durante a sua formação e na sua prática de refletir sobre suas concepções e crenças favorece a discussão crítica das situações de ensino e aprendizagem em Ciências. É o que faz a escola pesquisada em reuniões periódicas, em que se constatam a participação ativa e o envolvimento dos docentes.

A escola também revelou um ambiente propício à realização de atividades práticas, o qual foi confirmado pelos professores. Ela possui espaços escolares diferenciados (laboratório de Ciências; espaços para horta e jardim; pátio; sala multiuso; quadra e sala de leitura), professores em constante formação e uma gestão participativa. Outros dois fatores que nos chamaram a atenção foram o acoIhimento dos alunos e os equipamentos tecnológicos disponíveis. Por fazer parte do $\mathrm{PEl}$, a escola tem muitos recursos físicos e pedagógicos quando comparados às outras unidades estaduais que não fazem parte do mesmo programa. Esse é um aspecto positivo evidenciado pelos docentes e que auxilia no trabalho docente.

Nas aulas, pudemos perceber que os professores que assumiram uma postura mediadora e que estimularam o clima de desafio tiveram resultados mais satisfatórios nas atividades realizadas, com alunos mais participantes, curiosos e motivados em aprender.

Encontramos um fator que consideramos paradoxal na realidade dessa escola, a predileção por demonstrações e experimentos de caráter ilustrativo. Muitos motivos podem ser aventados para a carência de investigação nas aulas observadas, todavia acreditamos que exista uma dificuldade em estruturar atividades instigantes, isto é, que proporcionem questionamentos, o estabelecimento de relações, a compreensão do que estão produzindo, que exijam o escrever, enfim, que avivem o espírito científico. Talvez essa constatação explique a desmotivação de alguns alunos durante as aulas e até a indisciplina que observamos em determinados momentos.

\section{CONCLUSÃO}

Na visão dos professores, durante as entrevistas realizadas, as atividades práticas são importantes para estimular a observação e a curiosidade, permitindo a maior compreensão dos conteúdos e a melhoria na aprendizagem científica. Resumidamente, podemos concluir que as atividades práticas podem contribuir para melhoria na aprendizagem científica, desde que bem planejadas e pautadas 
por situações que promovam a curiosidade e a investigação. Além disso, os professores pesquisados relataram que a formação inicial os preparou para trabaIhar com atividades práticas na escola, mas salientam que continuar estudando é essencial para o exercício docente. Por último, vale ressaltar que uma gestão escolar participativa alicerça o trabalho docente.

O conjunto das análises realizadas nos levou a uma incursão sobre a relevância da ampliação da jornada escolar para o trabalho com atividades práticas. Até que ponto as condições apresentadas pela escola pesquisada contribuíram para a aprendizagem científica e na formação e prática docente? A resposta para essa questão não é simples, pois o aumento do tempo na escola não é garantia para o sucesso no ensino de Ciências, ele tem que contemplar a participação efetiva dos alunos e, também, fatores primordiais observados na pesquisa: uma escola com boa infraestrutura; gestão participativa; professores em formação contínua e comunidade presente.

\section{REFERÊNCIAS}

ALARCÃO, I. Escola reflexiva e nova racionalidade. Porto Alegre: Artmed Editora, 2001.

ANDRADE, M. L. F.; MASSABNI, V. G. O desenvolvimento de atividades práticas na escola: um desafio para os professores de Ciências. Ciência \& Educação, Bauru, v. 17, n. 4, p. 835-54, 2011.

ANDRÉ, M. O que é um estudo de caso qualitativo na educação? Revista da FAEEBA, Salvador, v. 22, n. 40, p. 95-103, 2013.

BEJARANO, N. R. R.; CARVALHO, A. M. P. Professor novato, suas crenças e conflitos. Investigações em Ensino de Ciências, Porto Alegre, v. 8, n. 3, p. 257-80, 2003.

BIZZO, N. Ciências: fácil ou difícil? São Paulo: Editora Ática, 2002.

BIZZO, N. Formação de professores de Ciências no Brasil: uma cronologia de improvisos. In: Ciência e Cidadania: Seminário Internacional Ciência de Qualidade para Todos. Brasília: UNESCO, 127-48, 2005.

BRASIL. Secretaria de Educação Fundamental. Parâmetros Curriculares Nacionais: Ciências Naturais. Brasília: MEC/SEF, 1998. 
CARVALHO, A. M. P.; GIL-PÉREZ, D. A formação de professores de Ciências: tendências e inovações. São Paulo: Cortez, 2011.

DELIZOICOV, D.; ANGOTTI, J. D.; PERNAMBUCO, M. M. Ensino de Ciências: fundamentos e métodos. São Paulo: Cortez, 2011.

DOURADO, L. Trabalho Prático (TP), Trabalho Laboratorial (TL), Trabalho de Campo (TC) e Trabalho Experimental (TE) no Ensino das Ciências - contributo para uma clarificação de termos. In: VERÍSSIMO, A; PEDROSA, A; RIBEIRO, R. (Org.). Ensino Experimental das Ciências. Porto: Departamento de Ensino Secundário; Ministério da Educação de Portugal, 2001. p. 13-18.

HODSON, D. Experimentos na ciência e no ensino de Ciências. Educational Philosophy and Theory, v. 20, p. 53-66. 1988. [Tradução de Paulo A. Porto]. Disponível em: http://www.iq.usp.br/palporto/TextoHodsonExperimentacao. Acesso em: 10 de abril de 2016.

KRASILCHIK, M. Reformas e realidade: o caso do ensino das Ciências. São Paulo em Perspectiva, São Paulo, v. 14, n. 1, p. 85-93, 2000.

KRASILCHIK, M. O professor e o currículo das Ciências. São Paulo: EPU, 2012.

LEITE, L. O trabalho laboratorial e a avaliação das aprendizagens dos alunos. In: SEQUEIRA, M. et al. (Org.). Trabalho prático e experimental na educação em Ciências. Braga: Universidade do Minho, 2000. p. 91-108.

PONTE, J. P. Concepções de professores de Matemática e processos de formação. In: PONTE (Ed.). Educação Matemática: temas de investigação. Lisboa: Instituto de Inovação Educacional, 1992. p. 185-239.

POZO, J. I.; CRESPO, M. A. G. A aprendizagem e o ensino de Ciências. Porto Alegre: Artmed, 2009.

PRAIA. J.; CACHAPUZ, A.; GIL-PÉREZ, D. A hipótese e a experiência científica em educação em ciência: contributos para uma reorientação epistemológica. Ciência \& Educação, Bauru, v. 8, n. 2, 2002. p. 253-62.

VILLANI, A. Planejamento Escolar: um instrumento de atualização dos professores de Ciências. Revista Ensino de Física, São Paulo, v. 13, 1991, p. 162-177. 


\section{Sobre os autores:}

Sandra Aparecida de Oliveira Souza - Mestrado em Educação, Arte e História da Cultura pela Universidade Presbiteriana Mackenzie. Especialização em Ensino de Ciências pela Universidade de São Paulo. Graduação em Pedagogia pela Universidade Vale do Rio Verde de Três Corações, e graduação em Ciências Biológicas pela Universidade São Judas Tadeu. Experiência na área de Educação, com ênfase em Ensino de Ciências. E-mail: sanvla@uol.com.br, Orcid: http://orcid.org/0000-0002-0788-1045

Maria de Fátima Ramos Andrade - Pós-doutorado em Políticas e Práticas da Educação Básica e Formação de Professores pela Fundação Carlos Chagas. Doutorado em Comunicação Semiótica pela Pontifícia Universidade Católica de São Paulo (PUC/SP). Mestrado em Educação pela Universidade de São Paulo. Graduação em Pedagogia pela PUC/SP. Atua em cursos de graduação e pós-graduação em Educação. Desenvolve pesquisas sobre os seguintes temas: Desenvolvimento profissional da docência, Alfabetização, Educação infantil, Educação a distância, Linguagem audiovisual, cinema de animação (textos multimodais). E-mail: mfrda@uol.com.br, Orcid: http://orcid.org/0000-0003-4945-8752

Recebido em julho de 2018

Aceito em maio de 2019 